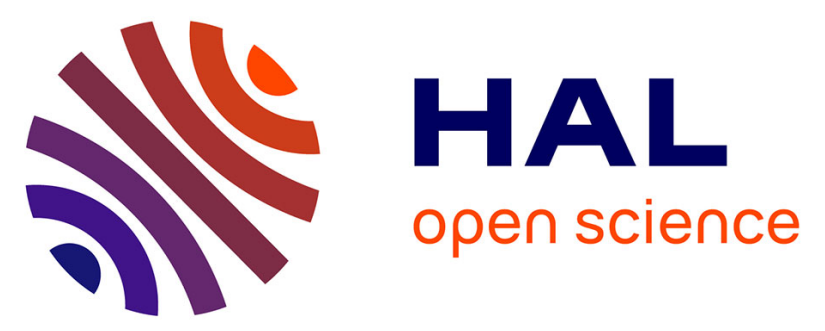

\title{
Application Feasibility Analysis of Precision Agriculture in Equipment for Controlled Traffic Farming System: A Review
}

Caiyun Lu, Zhijun Meng, Xiu Wang, Guangwei Wu, Nana Gao, Jianjun Dong

\section{- To cite this version:}

Caiyun Lu, Zhijun Meng, Xiu Wang, Guangwei Wu, Nana Gao, et al.. Application Feasibility Analysis of Precision Agriculture in Equipment for Controlled Traffic Farming System: A Review. 9th International Conference on Computer and Computing Technologies in Agriculture (CCTA), Sep 2015, Beijing, China. pp.348-355, 10.1007/978-3-319-48357-3_34 . hal-01557801

\section{HAL Id: hal-01557801 \\ https://hal.inria.fr/hal-01557801}

Submitted on 6 Jul 2017

HAL is a multi-disciplinary open access archive for the deposit and dissemination of scientific research documents, whether they are published or not. The documents may come from teaching and research institutions in France or abroad, or from public or private research centers.
L'archive ouverte pluridisciplinaire HAL, est destinée au dépôt et à la diffusion de documents scientifiques de niveau recherche, publiés ou non, émanant des établissements d'enseignement et de recherche français ou étrangers, des laboratoires publics ou privés.

\section{(c)(1)}

Distributed under a Creative Commons Attribution| 4.0 International License 


\title{
Application Feasibility Analysis of Precision Agriculture in Equipment for Controlled Traffic Farming System: A Review
}

\author{
Caiyun $\mathrm{Lu}^{1,2,3,4,5, \mathrm{a}}$, Zhijun Meng ${ }^{1,2,3,4, \mathrm{~b},{ }^{*}}$, Xiu Wang ${ }^{1,2,3,4, \mathrm{c}}$, Guangwei $\mathrm{Wu}^{1,2,3,4, \mathrm{~d}}$, Nana \\ $\mathrm{Gao}^{1,2,3,4, \mathrm{e}}$, Jianjun Dong ${ }^{1,2,3,4, \mathrm{f}}$ \\ ${ }^{1}$ Beijing Research Center of Intelligent Equipment for Agriculture, Beijing Academy of \\ Agriculture and Forestry Sciences, Beijing 100097, China; ${ }^{2}$ National Research Center of \\ Intelligent Equipment for Agriculture, Beijing 100097, China; ${ }^{3}$ Beijing Key Laboratory of \\ Intelligent Agricultural Equipment and Technology, Beijing 100097, China; ${ }^{4}$ Key Laboratory \\ of Agr-Informatics, Ministry of Agriculture, P. R. China, Beijing 100097, China; ${ }^{5}$ Beijing \\ Research Center for Information Technology in Agriculture, P. R. China, Beijing 100097, \\ China \\ alucy@nercita.org.cn, ${ }^{b}$ mengzj@nercita.org.cn, ${ }^{c}$ wangx@nercita.org.cn, \\ dwugw@nercita.org.cn, ${ }^{\mathrm{e}}$ gaonn@nercita.org.cn, ${ }_{\mathrm{f}}$ dongjj@nercita.org.cn
}

\begin{abstract}
Equipment includes planter, field management equipment and harvester for controlled traffic farming system is elaborated in the paper. And the analysis results shows that main problems of equipment for controlled traffic farming system contains poor ability to navigate, uneven and bent wheel lanes. To solve the problem, the thought that precision agriculture is introduced into equipment for controlled traffic farming system is put forward. For this purpose, the key technology of precision agriculture is introduced, and the feasibility of combination of precision agriculture and controlled traffic farming system is discussed, which provides theoretical support for the development of equipment for controlled traffic farming system.
\end{abstract}

Keywords: Controlled traffic farming system, equipment, precision agriculture

\section{Introduction}

Controlled traffic farming system, as a new agricultural production system, combines the conservation tillage and controlled traffic technology. The principle includes that crop zone is independent of wheel lane, which means wheels of tractor and machines run only on permanent lanes, and crop is planted on other soil except wheel lanes. So the crop will not be compacted by wheels, which can keep better environment for crop growth. Controlled traffic farming system requires few tillage to keep the lanes, no tillage and straw cover to realize water saving, waterlogging, tillage reduction and residue management before planting. Controlled traffic farming system was developed from Mexico, and has developed in many countries, which suffer drought and waterlogging. 
Researches show that controlled traffic farming system has many effects $[1,2]$. Wheel traffic can increase soil compaction which has negative influences on some critical soil properties, like saturated hydraulic conductivity, porosity and bulk density [3-6]. Bai et al. (2008) showed that 9 years controlled traffic farming system reduced bulk density $11.2 \%$, and increased porosity in $0-15 \mathrm{~cm}$ soil layer. In addition, the saturated hydraulic conductivity was greater under controlled traffic farming system [7]. Research by Chen et al. (2008) indicated that controlled traffic farming system prominently improved microbial biomass, soil organic matter and total $\mathrm{N}$ in $0-5 \mathrm{~cm}$ soil layer and the yield increased $10 \%$ greater than conventional tillage [8].

The development of controlled traffic farming system bases on mechanization, for example, key operations such as ridge reforming and reshaping and planting can't be completed by manual. Extending controlled traffic farming system will be meaningless without mechanization, and mechanized controlled traffic farming system is the inevitable trend. The equipment for controlled traffic farming system includes planter, field management equipment and harvester etc. There must be any method to guide the tractor and agricultural equipment running on the wheel lane rather than crop zone due to the separated crop zone and wheel lane. The development of controlled traffic system is still in its infancy, and the corresponding equipment is not mature. The guidance is mainly completed by artificial marking, and the method only suits short field, and the ability of guidance is bad, and wastes time and energy.

Based on the positioning and navigation, precision agriculture manages each growth process and controls agriculture products, such as fertilizer, pesticide and seed, etc. to fulfill a full potential of soil and crop. Precision agriculture is comprised of 10 systems, including global positioning system (GPS), geographic information system (GIS), remote sensing (RS), field information collecting system, intelligent agricultural system, expert system, system integration, environmental monitoring system, network management system, and communication system. And GPS, GIS, RS and computer control system are the core of the precision agriculture [9-12]. The attribute data, which comes from the analysis of soil and crop information by GIS, and map data can make field management information system. On the basis, input is adjusted according to actual conditions on each unit to reduce waste, increase income and protect environment. GPS, one of the cores of the precision agriculture, is used for accurate positioning of agricultural machine. The application of precision agriculture in controlled traffic farming system can realize accurate orientation, which is conducive to the demonstration and application of controlled traffic.

Basis on the literature at home and abroad, the paper introduces equipment for controlled traffic farming system and the existing problems, and elaborates the key technology of precision agriculture. On the basis, application feasibility of precision agriculture on equipment for controlled traffic farming system is discussed.

\section{Equipment for Controlled Traffic Farming System}

The research of equipment for controlled traffic farming system focuses on machines, and aims to avoid blockage by mulch on the field. However, the research on how to ensure accurate wheel layout has rare research, which is more important to controlled traffic farming system [13]. 


\subsection{Planter}

(1) No-tillage maize and wheat seeder for controlled traffic farming system

2BMDF-2/7 no-tillage maize and wheat seeder for controlled traffic farming system is used for wheat or maize planting in double cropping area. The planter can complete straw chopping, furrowing, fertilizing, planting and compacting in one time. Furrowing and fertilizing are completed by opener, and the mulch is chopped by high speed cutter. Combination of high speed cutter and double-disc opener is designed to avoid blockage by straw and weed. The cutter can put into sides of openers, and take away downed straw and weed to avoid blockage. The sharp tip of tine opener can cut off or hitch stubble, and the cutter chops the stubble hitched by tip to avoid blockage.

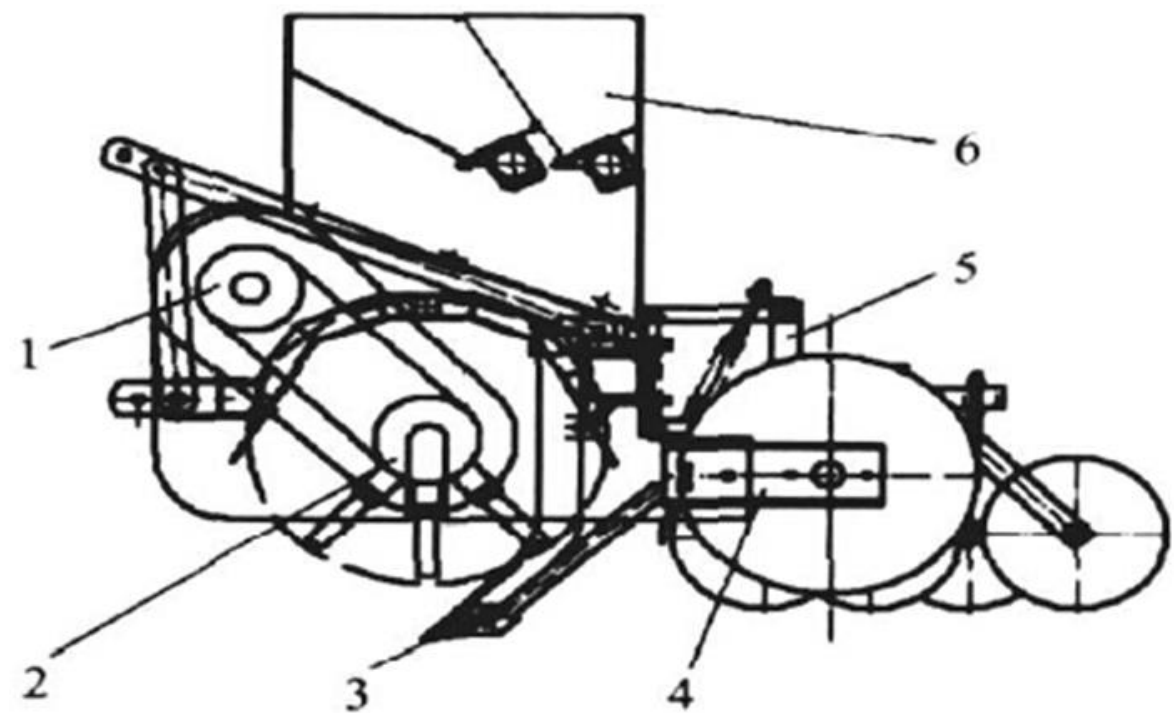

Fig. 1. 2BMDF-2/7 no-tillage maize and wheat seeder for controlled traffic farming system

(2) No-tillage fertilizing planter for controlled traffic farming system

2BMFSG-3/6 no-tillage fertilizing planter for controlled traffic farming system can plant wheat and maize with the mating power $300 \mathrm{HP}$ and working speed $3 \sim 5 \mathrm{~km} / \mathrm{h}$. The planter works on sunken controlled traffic, which means permanent raised bed farming system. Installation position of land wheel can be adjusted according to the depth of furrow to satisfy the requirements of sowing depth. The stubble and straw are cut by the rotary cutter. The diameter of land wheel is larger than that in flat field, and the installation position is lower, so that the furrow by opener satisfies the agronomy requirements when land wheel runs on the traffic lanes. The openers are distributed into two rows to avoid blockage [14]. 


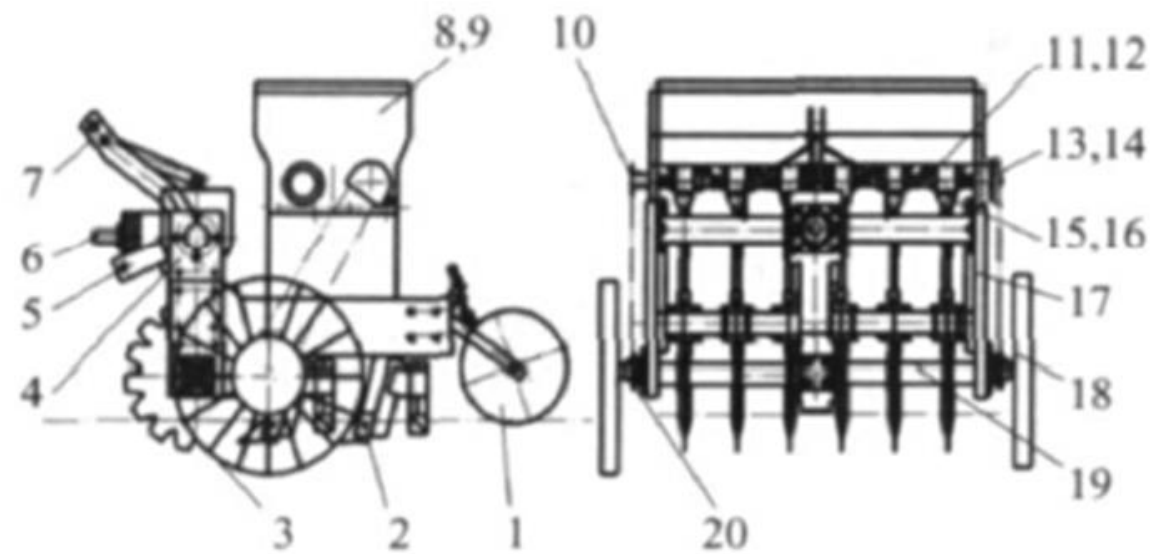

Fig. 2. 2BMFSG-3/6 no-tillage fertilizing planter under controlled traffic farming system

\subsection{Field Management Equipment}

Mating equipment of controlled traffic farming system is developed from planters to sprayers and other field management equipment with the wide application of controlled traffic farming technology in the world.

Figure 3 shows the sprayer for sunken controlled traffic farming system in Mexico. The spraying is finished during crop growth season to control weed and insects; furrow is used for guide, which improves the spraying with overlap and misses [2].

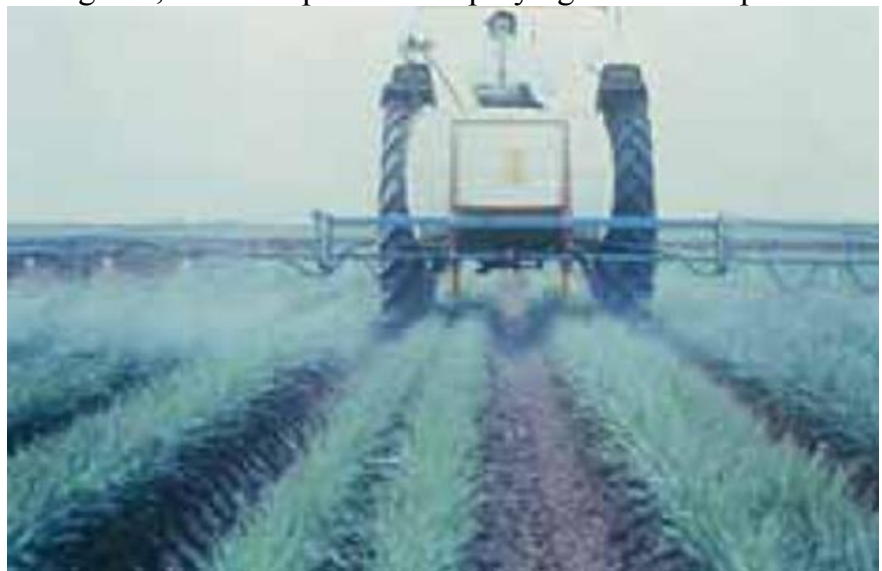

Fig. 3. Mexico sprayer for sunken controlled traffic farming system

\subsection{Harvester}

To improve efficiency of crop harvest, harvester for controlled traffic farming system is researched in the world, such as hanging harvester developed by China Agricultural 
University and two-row ridge harvester in Mexico. These two harvesters can not only ensure the harvest quality, but also keep ridge bed [2].

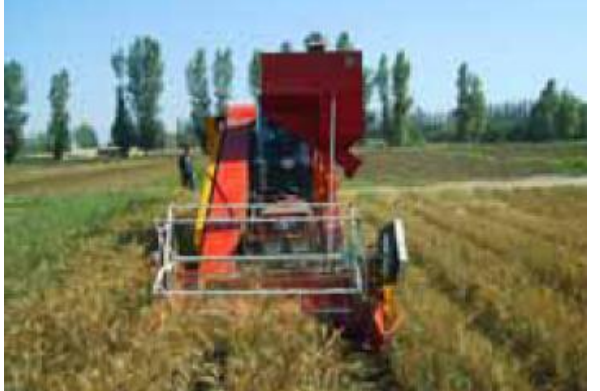

Fig. 4. Hanging harvester in China

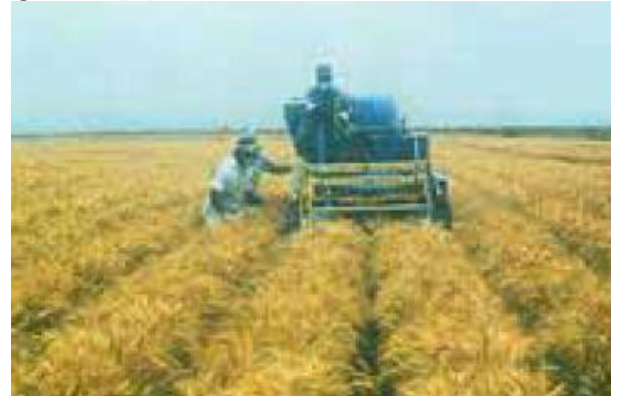

Fig. 5. Two-row ridge harvester in Mexico

\section{Key Technology of Precision Agriculture}

Precision agriculture was put forward in the 1990s by soil scientists in the University of Minnesota, America. After years of development, precision agriculture has developed in many aspects, including variable rate fertilization, nutrient detection, and yield monitoring, etc. The key technology of precision agriculture mainly includes:

\subsection{Global Positional System}

Global positioning system (GPS) refers to a satellite navigation system based on space, which can provide spatial and temporal information in all climatic situations, and anyplace where has a clear line of sight to at least four GPS satellites. This system can provide key capabilities for military, civilian, and commercial users all over the world. It was established and maintains by the United States government, and it is freely accessible to anyone who has a receiver. In 1973, the United States began the GPS project to overcome the restrictions of previous navigation systems, integrates advanced technologies from a few predecessors, and includes some classified engineering design studies in the 1960s. The system initially used 24 satellites. And it was completely operable in $1995[15]$.

Global positional system has following functions in precision agriculture: measurement controlling, field information sampling positioning and navigation control [16]. The research of GPS mainly focuses on field information sampling and intelligent agricultural machinery system with GPS receiver. For example, GPS receiver is installed on rotary tiller, planter, field sampler, fertilizing sprayer and harvester, which can obtain accurate positioning information navigation monitoring, and get crop growth information and associated spatial position information [17-18]. 


\subsection{Geographic Information System}

Geographic information system (GIS) is the core of precision agriculture, which is used for field data management, query of soil, natural condition, crop growth and yield etc., and agriculture theme maps drawing, as well as spatial data collecting and analyzing. In addition, GIS system can combine various data into new data sets, for example, GIS system deals with soil type, terrain, and mulch, and establishes the connection among them.

GIS system is software for dealing with spatial information for organizing, analyzing and showing all types of spatial information in the same area. Each kind of information can form one GIS layer, and information from different layers can form new layer by analysis. GIS system can combine various element maps into new map, and analyze the effect of various factors on crop. Take variable fertilizing for example; fertilizer rate is made in different site according to soil nutrition and yield, which guides the fertilizing [19].

\subsection{Remote Sensing}

Remote sensing (RS) refers to remote probing techniques. It uses sensors detecting electromagnetic waves, visible light and infrared rays from distant, and obtains detection and identification information by data analysis. Remote sensing technology is the key tool for large area obtaining field data rapidly in precision agriculture. It can support vast field spatial change information.

Remote sensing technology is an advanced probing techniques based on modern physics, space science, electronic computer technology, mathematics and earth scientific theory[20]. Various kinds of sensors were developed since 1900s, and both the probing ability and applying range have been significantly expanded.

Remote sensing mainly provides two types of crop and field spatial distribution information. One is basic information which has little change during crop growth season. The information mainly includes farm infrastructure, field contribution etc. And the other is dynamic change information of time and space, including yield, crop nutrition and insects, etc. [21]

\section{Application Feasibility Discussion of Precision Agriculture in Equipment for Controlled Traffic Farming System}

The research of equipment for controlled traffic farming system mainly focus on working performance with the assumption that wheel lanes exists and works well, and the tractor and equipment run on the wheel lanes. However, it is difficult to control the distance of two lanes constant, and the wheel lane is easy to bend during operation. In China, when the equipment works on the soil, it is guided by the distance location method of pulling a rope, which means that the ropes are pulled on the rim of lanes, and a person stands in the middle of the two traffic lanes at the end of the rows, and the operator takes the person as the orientation. This method guides the equipment 
staying on the traffic lanes. But it needs many labors, and is very inconvenient to pull a rope, so it only fits to the small-scale fields. In addition, the size of the overlap and the potential reduction by using controlled traffic farming system depends to a large extent on the individual driver's experience and skills with the precise handling of equipment and tractor tools prior to the introduction of auto steering. To solve the problems, precision agriculture is introduced to controlled traffic farming system [22].

Precision agriculture is a new agricultural technique to realize accurate fertilizing, sowing, irrigation and harvesting etc. with the GPS, GIS and RS. Farmers try hard to improve efficiency by increasing field size and machinery. Precision agriculture adoption on this scale has been made possible due to the enormous decrease of GPS equipment cost in recent years. Yield mapping can be accessed by the GPS system, and farmers could see the yield variation in real time occurring on the farm. Precision agriculture helps farmers to balance management with land capability to improve profitability and protect environmental resources [23].

\section{Conclusions}

Traditional equipment for controlled traffic farming system including planter, field management equipment and harvester is elaborated and the analysis results shows that main problems contain poor ability to navigate, uneven and bent wheel lanes. To solve the problems, the thought that precision agriculture is introduced into equipment for controlled traffic farming system and key technology of precision agriculture is introduced. Precision agriculture is a new agricultural technique to realize accurate fertilizing, sowing, irrigation and harvesting etc. with the GPS, GIS and RS. Farmers try hard to improve efficiency by increasing field size and machinery, which promote precision agriculture adoption. In addition, precision agriculture can help farmers to balance management with land capability to improve profitability and protect environmental resources. From this perspective, the application of precision agriculture in equipment for controlled traffic farming system is feasible.

\section{Acknowledgments}

This work was financed by the Postdoctoral Science Foundation of Beijing Academy of Agriculture and Forestry Sciences of China (2014002) and 863 Program (2012AA101901).

\section{References}

1. He Jin. Study on permanent raised beds in irrigation areas of Northern China[D]. Beijing: China Agricultural University, 2007.(in Chinese with English abstract) 
2. He Jin, Zheng Zhiqi, and Wang Qingjie. Current status of permanent raised beds equipment[J]. Journal of Agricultural Mechanization Research, 2014(9), 6-10. (in Chinese with English abstract)

3. Mathieu Lamande, Vincent Hallaire, Pierre Curmi, Guenola Peres, Daniel Cluzeau. Changes of pore morphology, infiltration and earthworm community in a loamy soil under different agricultural managements. Catena, 2003, 54, 637-649.

4. Pagliai M, Vignozzi N, Pellegrini S. Soil structure and the effect of management practices. Soil \& Tillage Research, 2004, 79, 131-143.

5. Radford BJ, Bridge BJ, Davis RJ, McGarry D, Pillai UP, Rickman JF, Walsh PA, Yule DF. Changes in the properties of a Vertisol and responses of wheat after compaction with harvester traffic. Soil \& Tillage Research, 2000, 61, 157-166.

6. Timothy R. Green, Lajpat R. Ahuja, Joseph G. Benjamin. Advances and challenges in predicting agricultural management effects on soil hydraulic properties. Geoderma, 2003, 116, 3-27.

7. Bai Yuhua, Chen Fu, Li Hongwen, Chen Hao, He Jin, Wang Qingjie, Tullberg JN, Gong Yuanshi. Traffic and tillage effects on wheat production on the Loess Plateau of China: 2. Soil physical properties. Australian Journal of Soil Research, 2008, 46, 652-658.

8. Chen Hao, Bai Yuhua, Wang Qingjie, Chen Fu, Li Hongwen, Tullberg JN, Murray JR, Gao Huanwen, Gong Yuanshi. Traffic and tillage effects on wheat production on the Loess Plateau of China: 1. Crop yield and SOM. Australian Journal of Soil Research, 2008, 46, 645-651.

9. Li Yaqin, Xia Feng. The necessity analysis of the development of precision agriculture in China[J]. Journal of Agricultural Mechanization Research, 2006( 6), 4-6. (in Chinese with English abstract)

10. Wang Maohua. Development of precision agriculture and innovation of engineering technologies[J]. Transactions of the CSAE, 1999, 15(1): 7-14. (in Chinese with English abstract)

11. Zhao Chunjiang, Xue Xuzhang, Wang Xiu, Chen Liping, Pan Yuchun, Meng Zhijun. Advance and prospects of precision agriculture technology system[J]. Transactions of the CSAE, 2003, 19(4): 7-12. (in Chinese with English abstract)

12. Kuang Pusheng, Liu Gang, Kuang Jishuang. On the precision agriculture technological system[J]. Transactions of the CSAE, 1999, 15(3): 1-4. (in Chinese with English abstract)

13. Chen Hao, Huang Hu, Yang Yali, Li Hongwen. Design of row-followed no-till wheat and maize planter under controlled traffic farming system[J]. Transactions of the Chinese Society for Agricultural Machinery, 2009, 40(3): 72-76. (in Chinese with English abstract)

14. Tian Bin, Han Shaoping, Wu Jianmin. Design of 2 BMFSG-3/6no-till fertilizing planter under controlled traffic farming system $[\mathrm{J}]$. Transactions of the Chinese Society for Agricultural Machinery,2007, 38(6): 187-189, 198.

15. https://en.wikipedia.org/wiki/Global_Positioning_System.

16. Pan Yuchun, Zhao Chunjiang. Application of geographic information technologies in precision agriculture[J]. Transactions of the CSAE, 2003, 19(4): 1-6.

17. Blackmore BS. An information system for precision farming. Presented at the Brighton Conference Pests and Diseases[J]. British crop Protection Council. November, 1996: 18-21.

18. Wang Shen, Liu Deying. Research on application of $3 \mathrm{~S}$ in precision agriculture[J]. Journal of Hotan Normal School, 2006, 26(5): 166-167. (in Chinese with English abstract)

19. Xu SX, Du JQ. Application of geographic information system in precision agriculture[J]. Modern Agriculture, 2003(2): 33-34.

20. Diofantos G. Hadjimitsis. Advances in remote sensing and geo-information for the environment[J]. Central European Journal of Geosciences, 2014, 6(1): 1.

21. Shi Zhou, Liang Zongzheng, Yang Yuanyuan, Guo Yan. Status and prospect of agricultural remote sensing[J]. Transactions of the Chinese Society for Agricultural Machinery, 46(2): 247-260. 
22. Mark. Using conservation agriculture and precision agriculture to improve a farming system[M]. Rainfed Farming Systems, 2011: 875-900.

23. Hans GJ, Jacobsen LB, Soren MP, Elena T. Socioeconomic impact of widespread adoption of precision farming and controlled traffic systems in Demark[J]. Precision Agriculture, 2012, 13: 661-677. 